Finance and Economics Discussion Series

Divisions of Research \& Statistics and Monetary Affairs

Federal Reserve Board, Washington, D.C.

\title{
External Habit and the Cyclicality of Expected Stock Returns
}

\section{Thomas D. Tallarini, Jr. and Harold H. Zhang \\ 2005-27}

NOTE: Staff working papers in the Finance and Economics Discussion Series (FEDS) are preliminary materials circulated to stimulate discussion and critical comment. The analysis and conclusions set forth are those of the authors and do not indicate concurrence by other members of the research staff or the Board of Governors. References in publications to the Finance and Economics Discussion Series (other than acknowledgement) should be cleared with the author(s) to protect the tentative character of these papers. 


\title{
External Habit and the Cyclicality of Expected Stock Returns*
}

\author{
Thomas D. Tallarini, Jr. ${ }^{\dagger} \quad$ Harold H. Zhang ${ }^{\ddagger}$
}

May 2005

\begin{abstract}
We estimate an equilibrium asset pricing model in which agents' preferences have an unobserved external habit using the efficient method of moments (EMM). Given the estimated structural parameters we examine the cyclical behavior of expected stock returns in the model. We find that the estimated structural parameters imply countercyclical expected stock returns as documented in existing empirical studies. The model, however, is still rejected at the one percent level. Detailed examination of the moment conditions in our estimation indicates that the model performs reasonably well in matching the mean of returns, but it fails to capture the higher order moments.
\end{abstract}

JEL Classification: G12

Keywords: external habit, expected returns, asset pricing, Efficient Method of Moments

*We thank Ronald Gallant and George Tauchen for providing us the EMM code, John Campbell, John Cochrane, Dave DeJong, Wayne Ferson, Rene Garcia, Lars Hansen, Paul Harrison, John Heaton, Ming Liu, Adrian Pagan, Amir Yaron, Stan Zin, and the seminar participants at Carnegie Mellon University, the Chinese University of Hong Kong, and the University of Pittsburgh for helpful comments. The paper was presented at the Second International Conference on Computing in Economics and Finance in Geneva, Switzerland, the Far Eastern Meetings of the Econometric Society in Hong Kong, and the North American Summer Meetings of the Econometric Society in Montreal. The standard disclaimer applies. The views presented are solely those of the authors and do not necessarily represent those of the Federal Reserve Board or its staff.

${ }^{\dagger}$ Corresponding author. Division of Research and Statistics, Federal Reserve Board, Washington, DC 20551. Phone: (215) 898-3609. Email: thomas.d.tallarini@frb.gov.

${ }^{\ddagger}$ Kennan-Flagler Business School, University of North Carolina, Chapel Hill, NC 27599. Phone: (919) 843-8340. Email: zhangha@kenan-flagler.unc.edu. 


\section{Introduction}

Expected stock returns are related to the business cycle as shown in papers by Fama and French (1989), Fama (1990), Kandel and Stambaugh (1990), and Harrison and Zhang (1999), and others. In fact, expected returns are countercyclical: higher in recessions and lower in booms. Much of this research has focused on identifying the cyclicality of expected returns without attempting to explain it. 'Standard' models with time separable utility and exogenous endowment processes tend to generate procyclical returns. This is the finding reported in Kandel and Stambaugh (1990). This result is robust to a variety of extensions. Balvers, Cosimano, and McDonald (1990) introduce production, and Zhang (1997) introduces heterogeneous agents and incomplete markets with short-sale constraints into the model examined by Kandel and Stambaugh (1990), both finding that expected stock returns remain procyclical.

Campbell and Cochrane (1999) show that relaxing time separability in preferences can generate countercyclical returns. The mechanism they propose is a slow-moving, non-linear external habit. The representative agent's utility is now a function of current private consumption as well as current and past aggregate consumption. Since the habit is external, individual agents do not consider the effects of current consumption on future utility. The set-up is similar in spirit to Abel's (1990) 'catching up with the Joneses' framework. The habit process moves more slowly than consumption so that in a downturn, consumption falls faster than the habit resulting in an increase in local risk aversion. In an expansion, the opposite happens. The countercyclical effect on risk aversion results in a countercyclical pattern for risk premia and therefore countercyclical expected returns. This explanation is consistent with Black (1990) who argues that risk aversion should be higher in recessions when wealth is low. However, Ljungqvist and Uhlig (1999) show that the Campbell and Cochrane specification implies consumption bunching. This is the result of the habit moving negatively with consumption with these preferences when consumption is endogenous. More standard 'catching up with the Joneses' preferences have consumption and habit moving together. In a Campbell and Cochrane world, a benevolent government counteracts the externality by inducing cycles while in a more standard catching-up world, the benevolent government stabilizes the economy (Ljungqvist and Uhlig (2000)).

In this paper, we estimate the model proposed by Campbell and Cochrane (1999). We use the efficient method of moments (EMM) proposed by Gallant and Tauchen (1996). The EMM is in the same spirit to the 'Indirect Inference' method proposed by Smith (1993) and Gourieroux, Monfort, and Renault (1993). This not only allows us to pin down the structural parameters of interest, but also permits a detailed assessment of the performance 
of the economic model in matching observed stock returns. The estimation method is based on simulation and allows us to handle the unobserved external habit with relative ease. In a similar situation, Eichenbaum and Hansen (1990) propose that an initial guess for the unobserved variable be used and then the Generalized Method of Moments (GMM) be applied. Following this approach in our case may lead to poor estimates and statistical inference. In particular, the external habit is extremely persistent. Given the small sample size, initial conditions will have a strong effect on the estimates of the other parameters. Since the EMM estimator is simulation-based, we can remove the effect of initial conditions on the persistent habit process by discarding a long series of simulated realizations of returns before we start to collect observations used in our EMM estimation. Specifically, for numerical tractability, we take a two-step approach by first estimating the exogenous driving processes consisting of consumption growth and dividend growth using a vector autoregression. We then estimate the structural parameters such as the discount factor, the risk aversion coefficient, and the persistence parameter for the surplus consumption ratio using the EMM and the exogenous driving processes estimated in the first step.

Using the estimated structural parameters, we then investigate the cyclicality of expected stock returns implied by the economic model at various holding intervals. We first provide some benchmark results on the cyclical behavior of expected returns of the S\&P 500 index portfolio at various holding intervals from one quarter to five years. This is done in two steps. In the first step, we obtain the expected holding returns by regressing compounded stock returns on a set of information variables such as the dividend yield, earning-price ratio, default premium, and term premium. In the second step, we regress the expected holding returns on a business cycle proxy as in Harrison and Zhang (1999) to quantify the comovements with business cycles. To examine the cylicality of expected stock returns implied by the economic model, we obtain long series of the expected holding returns at the same holding intervals as for the data using Monte Carlo integration. We then regress the expected holding returns on the business cycle dummy variables constructed for the economic model using the methodology suggested in Rouwenhorst (1995) to quantify their cyclical behavior.

We find that the estimated subjective discount factor is slightly and statistically significantly above one. This result supports the finding reported in Kocherlakota (1990). The estimated persistence parameter for the surplus consumption ratio is statistically significantly above 0.9 indicating the existence of a slow-moving external habit. The economic model with the external habit is rejected at the 1 percent level (but not at the 0.1 percent level). Detailed examination of the moment conditions (both the scores and the conventional moments) indicates that the economic model matches reasonably well the mean stock returns 
but it fails to match the higher order moments such as variance, skewness, and kurtosis. The external habit implied by the estimated structural parameters generates countercyclical expected stock returns at longer horizons such as one year, two years, and five years. This is driven by the fact that the surplus consumption ratio reacts strongly positively to the contemporaneous consumption growth rate. This implies that the external habit moves at a much slower rate than consumption. The consumption and habit differential thus decreases and agents' local risk aversion increases in recessions. High expected returns are needed to induce agents to hold stocks. Finally, the curvature parameter (the coefficient of relative risk aversion in a time separable environment) has a point estimate of 6.27 which is more than three times the value chosen by Campbell and Cochrane and outside what is generally considered to be the reasonable range for this parameter.

Consistent with the finding that the economic model can match the mean stock returns reasonably well, we also find that the expected simulated stock returns during non-recession periods are comparable to the expected S\&P 500 index returns at various holding horizons ranging from one quarter to five years. The spread in expected returns between recession and non-recession periods implied in the economic model is much smaller than the counterpart for the S\&P 500 index. This is consistent with the finding that the economic model is unable to match the variance of the observed stock returns.

The rest of the paper is organized as follows. Section 2 presents the model and defines the law of motion for exogenous forcing variables. Section 3 presents and discusses the EMM estimation results and evaluates the performance of the model. Section 4 investigates the cyclicality of expected returns implied in the model, and Section 5 concludes the paper.

\section{Preferences with an External Habit}

There is an infinitely-lived representative agent who derives utility from consuming a single consumption good. Consumer's preferences depend on both the current consumption and some habit level. Let $C_{t}$ be the representative agent's consumption at time $t$ and $X_{t}$ be the agent's habit level at time $t$. Following Campbell and Cochrane, we assume that $X_{t}$ depends on economy wide per capita consumption rather than the agent's own consumption though in equilibrium the two are equal. The agent's objective is to maximize the expected sum of discounted future utility given as follows:

$$
\max E\left[\sum_{t=0}^{\infty} \beta^{t} \frac{\left(C_{t}-X_{t}\right)^{1-\gamma}-1}{1-\gamma}\right]
$$


where $\beta$ is the subjective discount factor and $\gamma$ is the curvature parameter. ${ }^{1}$

The habit level $X_{t}$ will evolve as specified by Campbell and Cochrane. It will be treated by individual agents as beyond their control and therefore a function of aggregate per capita consumption. It will follow a non-linear process in order to keep the habit below consumption $\left(X_{t}<C_{t}\right)$. Let $S_{t}$ denote the surplus consumption ratio:

$$
S_{t}=\frac{C_{t}-X_{t}}{C_{t}}
$$

We will use lowercase letters to denote the natural $\operatorname{logs}$ of variables $(x=\log X)$. As in Campbell and Cochrane, we assume that the surplus consumption ratio evolves according to:

$$
s_{t+1}=(1-\phi) \bar{s}+\phi s_{t}+\lambda\left(s_{t}\right)\left(\bar{c}_{t+1}-\bar{c}_{t}-g\right)
$$

where $\phi$ determines the persistence of the surplus consumption ratio, $\bar{s}$ is the steady state surplus consumption ratio, $\lambda\left(s_{t}\right)$ is the sensitivity function of the surplus consumption ratio to the contemporaneous per capita consumption growth rate, $\bar{c}_{t}$ is the log of per capita consumption which equals the consumption of the agent in equilibrium, and $g$ is the average economy wide per capita consumption growth rate.

The sensitivity function, $\lambda\left(s_{t}\right)$, takes the same form as in Campbell and Cochrane:

$$
\lambda\left(s_{t}\right)= \begin{cases}(1 / \bar{S}) \sqrt{1-2\left(s_{t}-\bar{s}\right)}-1, & s_{t}<s_{\max } \\ 0 & s_{t} \geq s_{\max }\end{cases}
$$

where $\bar{S}$, the steady state surplus consumption ratio, is given by $\sigma \sqrt{\frac{\gamma}{1-\phi}}$ where $\sigma$ is the standard deviation of consumption growth rate and $s_{\max }$, the upper limit for the surplus consumption ratio, is given by

$$
s_{\max }=\bar{s}+\frac{1}{2}\left(1-\bar{S}^{2}\right) .
$$

The implication of the above specification is that the risk-free rate is constant when the consumption growth rate is a log normal i.i.d. random variable, and the habit moves nonnegatively with consumption.

We consider a stock with dividend process $D_{t}$. The equilibrium stock price, denoted by

\footnotetext{
${ }^{1}$ Because of the presence of the external habit, the agent's local risk aversion coefficient is no longer $\gamma$ but rather a function of consumption and habit level.
} 
$P_{t}$, can then be expressed as:

$$
P_{t}=E_{t}\left[\beta\left(\frac{C_{t+1}-X_{t+1}}{C_{t}-X_{t}}\right)^{-\gamma}\left(P_{t+1}+D_{t+1}\right)\right]=E_{t}\left[\beta\left(\frac{S_{t+1}}{S_{t}}\right)^{-\gamma}\left(\frac{C_{t+1}}{C_{t}}\right)^{-\gamma}\left(P_{t+1}+D_{t+1}\right)\right]
$$

As in Campbell and Cochrane, we model consumption and dividends as separate processes. Since the growth rates of dividends and consumption are only weakly correlated in US data, it can be important to model dividends and consumption separately.

To induce stationarity, we normalize the stock price by dividends $\left(D_{t}\right)$. The normalization yields

$$
\tilde{P}_{t}=E_{t}\left[\beta\left(\frac{S_{t+1}}{S_{t}}\right)^{-\gamma}\left(\frac{C_{t+1}}{C_{t}}\right)^{-\gamma}\left(\tilde{P}_{t+1}+1\right)\left(\frac{D_{t+1}}{D_{t}}\right)\right]
$$

where $\tilde{P}_{t}=P_{t} / D_{t}$.

Comparing the pricing function above with the one without the external habit, we have introduced the term $\left(S_{t+1} / S_{t}\right)^{-\gamma}$ which decreases as the growth of the surplus consumption ratio increases. Since the growth of the surplus consumption ratio enters the pricing function exactly as consumption growth, we expect the former to affect the stock price and expected stock returns in the same way as the latter does. The important issue is how the surplus consumption ratio evolves as a function of contemporaneous consumption growth. If the growth of the surplus consumption ratio is highly correlated with per capita consumption growth, the stock price will be strongly procyclical and expected stock returns countercyclical.

The exogenous forcing variables in the model consist of the per capita consumption growth rate $\left(\Delta c_{t}=\bar{c}_{t}-\bar{c}_{t-1}\right)$ and dividend growth rate $\left(\Delta d_{t}\right)$. We assume that the consumption and dividend growth rates follow a bivariate vector autoregressive (VAR) process with one lag, ${ }^{2}$ i.e.,

$$
\left[\begin{array}{l}
\Delta c_{t+1} \\
\Delta d_{t+1}
\end{array}\right]=\left[\begin{array}{l}
a_{1} \\
a_{2}
\end{array}\right]+\left[\begin{array}{ll}
b_{11} & b_{12} \\
b_{21} & b_{22}
\end{array}\right]\left[\begin{array}{c}
\Delta c_{t} \\
\Delta d_{t}
\end{array}\right]+\left[\begin{array}{l}
\epsilon_{1 t+1} \\
\epsilon_{2 t+1}
\end{array}\right]
$$

where $\left[\epsilon_{1 t}, \epsilon_{2 t}\right]^{\prime} \sim N(0, \Sigma)$. The sufficient state space for the above problem thus consists of consumption and dividend growth rates, and the surplus consumption ratio of the previous period. Denote by $z_{t}=\left[\Delta c_{t}, \Delta d_{t}\right]^{\prime}$ the vector of exogenous state variables. The one-step

\footnotetext{
${ }^{2}$ Campbell and Cochrane (1999) suggest that it would be better to make consumption and dividends cointegrated. They report that imposing cointegration does not significantly change their results while complicating some of calculations by introducing an additional state variable. Campbell and Cochrane assume that consumption and dividend growth rates are i.i.d., potentially correlated and have identical means. We relax the i.i.d. and identical mean assumptions in our specification, but we do not impose cointegration.
} 
ahead conditional density for $z_{t}$ is therefore a Gaussian with mean

$$
\left[\begin{array}{l}
a_{1} \\
a_{2}
\end{array}\right]+\left[\begin{array}{ll}
b_{11} & b_{12} \\
b_{21} & b_{22}
\end{array}\right]\left[\begin{array}{l}
\Delta c_{t} \\
\Delta d_{t}
\end{array}\right]
$$

and covariance matrix $\Sigma$. We can thus represent the state space by $\left(z_{t}, S_{t-1}\right)$. The stock price can then be written as

$$
\begin{aligned}
\tilde{P}\left(z_{t}, S_{t-1}\right)=E\left\{\beta\left[\frac{S\left(z_{t+1}, S\left(z_{t}, S_{t-1}\right)\right)}{S\left(z_{t}, S_{t-1}\right)}\right]^{-\gamma} \exp \left(\Delta c_{t+1}\right)^{-\gamma}\right. \\
{\left.\left[\tilde{P}\left(z_{t+1}, S\left(z_{t}, S_{t-1}\right)\right)+1\right] \exp \left(\Delta d_{t+1}\right) \mid z_{t}, S_{t-1}\right\} . }
\end{aligned}
$$

To estimate the bivariate VAR specification for the exogenous state variables, we construct quarterly per capita consumption growth rate of non-durables and services and per capita dividend growth rate adjusted by the population growth (age 16 and above) using the CITIBASE data from 1947:Q2 to 1995:Q3. Table 1 presents the estimation results. We make the following observations. Consumption growth at time $t$ is positively related to both consumption and dividend growth rates at time $t-1$. The estimates are statistically significant at the 5 percent level. While the dividend growth rate is also positively related to the lagged consumption and dividend growth rates, the estimates are not statistically significant at the conventional test level. In the next section, we formally estimate the economic model with the external habit and provide a statistical assessment of its performance in matching the observed stock returns.

\section{$3 \quad$ EMM Estimation of Structural Parameters}

\subsection{The EMM Estimator}

Our goal here is to jointly estimate the Euler equation and the law of motion for the external habit for a given exogenous driving force: ${ }^{3}$

$$
\begin{aligned}
\tilde{P}_{t} & =E_{t}\left[\beta\left(\frac{S_{t+1}}{S_{t}}\right)^{-\gamma}\left(\frac{C_{t+1}}{C_{t}}\right)^{-\gamma}\left(\tilde{P}_{t+1}+1\right) \frac{D_{t+1}}{D_{t}}\right], \\
s_{t+1} & =(1-\phi) \bar{s}+\phi s_{t}+\lambda\left(s_{t}\right)\left(\Delta \bar{c}_{t+1}-g\right),
\end{aligned}
$$

\footnotetext{
${ }^{3}$ The vector autoregressive process for the exogenous forcing variables is fixed at the point estimates reported in Table 1 when we estimate the structural parameters governing preferences. Thus, sampling errors in the first step estimation are not explicitly accounted for.
} 


$$
\lambda\left(s_{t}\right)= \begin{cases}(1 / \bar{s}) \sqrt{1-2\left(s_{t}-\bar{s}\right)}-1, & s_{t}<s_{\max } \\ 0, & s_{t} \geq s_{\max }\end{cases}
$$

Because the external habit is not observed, to apply the GMM as in Eichenbaum and Hansen (1990), one needs to jointly estimate the initial surplus consumption ratio $\left(s_{0}\right)$ and the other structural parameters. Using the S\&P 500 value weighted returns and the returns of ten decile portfolios in combination with the risk-free rate as the moment conditions, we find that the curvature parameter $(\gamma)$ estimate is in general quite small (less than 1.0 in most cases). It gets larger when the initial surplus consumption is fixed at the steady state level but it is still usually less than 3.0. All the models have a high $p$-value consistently above 10 percent implying that the model with an external habit cannot be rejected at conventional test levels. However, this may simply reflect that the model is poorly estimated when the surplus consumption ratio process is highly persistent and the sample size is too small. Indeed, the estimated persistence parameter $(\phi)$ is consistently above 0.98 implying strong persistence in the surplus consumption ratio process. The high persistence parameter estimate coupled with a relatively small sample size thus render the GMM estimation unreliable in this case. ${ }^{4}$

A simulation based generalization of GMM proposed in Bansal, Gallant, Hussey and Tauchen (1994) and Gallant and Tauchen (1996), the EMM, is well suited to the problem at hand. It allows us to remove the effect of the initial value of the surplus consumption ratio when the habit process is highly persistent and the sample size is small. This is achieved by first simulating a long series of exogenous variables, the consumption and dividend growth rates, and then recursively computing the surplus consumption ratio and the stock returns starting from an initial guess for the surplus consumption ratio. We discard the first several thousand simulated stock returns before we collect data for our EMM estimation. The idea of the EMM is to use the expectation under the structural model of the scores from an auxiliary model (called a score generator) as the vector of moment conditions. The scores are the derivatives of the log likelihood function of the auxiliary model with respect to its parameters. The estimator is defined as follows.

Let $\left\{\tilde{y}_{t}, \tilde{x}_{t-1}\right\}_{t=1}^{n}$ denote the observed data set (in our case, $\left\{\tilde{y}_{t}\right\}$ represents the S\&P 500 index return series), where $\tilde{x}_{t-1}=\left(\tilde{y}_{t-L}, \cdots, \tilde{y}_{t-1}\right)^{\prime}, L \geq 1$. Let $f\left(\tilde{y}_{t} \mid \tilde{x}_{t-1}, \theta\right), \theta \in \Theta \subset \Re^{l_{\theta}}$, be the one-step conditional density function which is the auxiliary model that generates scores for the economic model to match. Let $\rho \in \varrho \subset \Re^{l_{\rho}}$ be the vector of structural parameters to be estimated, and $\left\{\hat{y}_{\tau}(\rho), \hat{x}_{\tau-1}(\rho)\right\}_{\tau=1}^{N}$ be the counterpart of the observed data simulated from

\footnotetext{
${ }^{4}$ The GMM results are not reported to save space and are available upon request. Interestingly, the results are broadly consistent with the findings reported in Ferson and Constantinides (1991) for a model with an internal habit formation using quarterly data.
} 
the structural model given the structural parameters $\rho$. The simulated data can be obtained by numerically solving equations (10), (11), and (12) jointly for a given exogenous driving force. We choose to implement the parameterized expectations algorithm proposed by Den Haan and Marcet (1990), and applied in Bansal, Gallant, Hussey and Tauchen (1993) in connection with the simulated method of moments estimation. Specifically, we parameterize the right-hand-side of equation (10) as follows:

$$
E_{t}\left[\beta\left(\frac{S_{t+1}}{S_{t}}\right)^{-\gamma}\left(\frac{C_{t+1}}{C_{t}}\right)^{-\gamma}\left(\tilde{P}_{t+1}+1\right) \frac{D_{t+1}}{D_{t}}\right]=\exp \left[h\left(z_{t}, S_{t-1} ; \psi\right)\right]
$$

where $h\left(z_{t}, S_{t-1} ; \psi\right)$ is a polynomial in state variables $\left(z_{t}, S_{t-1}\right)^{\prime}$ and $\psi$ is a vector of parameters for the polynomial. In our application, we find the following quadratic polynomial to work very well:

$$
h\left(z_{t}, S_{t-1} ; \psi\right)=\psi_{0}+\psi_{1} \Delta c_{t}+\psi_{2} \Delta d_{t}+\psi_{3} S_{t-1}+\psi_{4} \Delta c_{t}^{2}+\psi_{5} \Delta d_{t}^{2}+\psi_{6} S_{t-1}^{2}
$$

We first estimate the auxiliary parameter $\theta$ using quasi-maximum likelihood estimation:

$$
\tilde{\theta}_{n}=\operatorname{argmax}_{\theta \in \Theta} \frac{1}{n} \sum_{t=1}^{n} \ln f\left(\tilde{y}_{t} \mid \tilde{x}_{t-1}, \theta\right) .
$$

This is achieved by solving the following set of first-order conditions:

$$
\frac{1}{n} \sum_{t=1}^{n}(\partial / \partial \theta) \ln f\left[\tilde{y}_{t} \mid \tilde{x}_{t-1}, \tilde{\theta}_{n}\right]=0
$$

The basic idea of EMM estimation is that under the null hypothesis that the structural model is correctly specified, there exists a true parameter vector $\rho^{0} \in \varrho$ such that the simulated data $\left\{\hat{y}_{\tau}\left(\rho^{0}\right), \hat{x}_{\tau-1}\left(\rho^{0}\right)\right\}_{\tau=1}^{N}$ also satisfy the above first-order conditions.

We thus introduce the moment conditions as follows:

$$
m_{n}\left(\rho, \tilde{\theta}_{n}\right)=\frac{1}{N} \sum_{\tau=1}^{N}(\partial / \partial \theta) \ln f\left[\hat{y}_{\tau}(\rho) \mid \hat{x}_{\tau-1}(\rho), \tilde{\theta}_{n}\right]
$$

The EMM estimator of the structural parameter vector is then defined analogously to the GMM estimator as follows:

$$
\hat{\rho}_{n}=\operatorname{argmin}_{\rho \in \varrho} m_{n}^{\prime}\left(\rho, \tilde{\theta}_{n}\right)\left(\tilde{\mathcal{I}}_{n}\right)^{-1} m_{n}\left(\rho, \tilde{\theta}_{n}\right)
$$


where $\left(\tilde{\mathcal{I}}_{n}\right)^{-1}$ is the weighting matrix and is given by the outer-product-of-gradient formula

$$
\tilde{\mathcal{I}}_{n}=\frac{1}{n} \sum_{t=1}^{n}\left[(\partial / \partial \theta) \ln f\left(\tilde{y}_{t} \mid \tilde{x}_{t-1}, \tilde{\theta}_{n}\right)\right]\left[(\partial / \partial \theta) \ln f\left(\tilde{y}_{t} \mid \tilde{x}_{t-1}, \tilde{\theta}_{n}\right)\right]^{\prime}
$$

Gallant and Tauchen (1996) show that the EMM estimator defined above is consistent and asymptotically normal, and the normalized objective value

$$
\tilde{s}_{n}\left(\hat{\rho}_{n}\right)=n m_{n}^{\prime}\left(\hat{\rho}_{n}, \tilde{\theta}_{n}\right)\left(\tilde{\mathcal{I}}_{n}\right)^{-1} m_{n}\left(\hat{\rho}_{n}, \tilde{\theta}_{n}\right)
$$

has an asymptotic chi-square distribution with degrees of freedom $l_{\theta}-l_{\rho}$, where $l_{\theta}$ and $l_{\rho}$ are the numbers of parameters in auxiliary and economic models, respectively.

Because the conditional density function, which serves as the auxiliary model, is usually unknown, in practice, it needs to be estimated. We employ the Gallant and Tauchen (1989) seminonparametric (SNP) method to estimate $f\left(\tilde{y}_{t} \mid \tilde{x}_{t-1}, \theta\right)$ along with the auxiliary parameter vector, $\theta$. Next, we provide the empirical estimation results.

\subsection{Empirical Results}

\subsubsection{SNP Density Estimate of Real Stock Returns}

In their baseline formulation, Campbell and Cochrane (1999) choose the sensitivity function $\lambda\left(s_{t}\right)$ so that the risk-free rate is constant and the habit moves nonnegatively with consumption. In an alternative formulation, they allow the risk-free rate to vary with the state variable, for instance, let the risk-free rate be a linear function of $\left(s_{t}-\bar{s}\right)$. However, Campbell and Cochrane show that adding interest rate variation in this way has very little effect on the stock market results. Following Campbell and Cochrane, we focus on the stock returns. ${ }^{5}$ Specifically, the series that we choose to match for our economic model is the quarterly real returns of the S\&P 500 index portfolio. The data spans the period from the second quarter of 1947 to the third quarter of 1995. The ex post real returns are obtained by adjusting the nominal returns of the S\&P 500 index portfolio by inflation. We estimate the conditional density function for the real returns using the SNP method which we briefly discuss below.

The SNP method is based on the notion that a Hermite expansion can be used as a general purpose approximation to a density function. This basic approach can be adapted to the estimation of the conditional density of the return series, denoted $\left\{y_{t}\right\}$, that has a Markovian structure - where the conditional density of $y_{t}$ given the entire history $\left\{y_{t-l}\right\}_{l=1}^{\infty}$ depends only on $L$ lags from the most recent past. Collecting these lags together in a single

\footnotetext{
${ }^{5}$ The implications for the risk-free rate will be discussed below.
} 
vector gives a $L$-vector denoted as $x_{t-1}$ :

$$
x_{t-1}=\left(y_{t-L}, \cdots, y_{t-2}, y_{t-1}\right)^{\prime} .
$$

The SNP approximation of a density takes the following form:

$$
f\left(y_{t} \mid x_{t-1}, \theta\right)=\frac{1}{\xi}\left[P\left(z_{t}, x_{t-1}\right)\right]^{2} n\left(y_{t} \mid \mu_{x_{t-1}}, \sigma_{x_{t-1}}\right)
$$

where $\xi$ is a scalar that makes the density integrate to one, ${ }^{6} z_{t}=\sigma_{x_{t-1}}^{-1}\left(y_{t}-\mu_{x_{t-1}}\right)$ is an innovation, $P\left(z_{t}, x_{t-1}\right)$ denotes a polynomial in $z_{t}$ of degree $K_{z}$ whose coefficients are polynomials of degree $K_{x}$ in $x_{t-1}, n\left(y_{t} \mid \mu_{x_{t-1}}, \sigma_{x_{t-1}}\right)$ is a normal distribution with mean $\mu_{x_{t-1}}$ (the location function) and standard deviation $\sigma_{x_{t-1}}$ (the scale function) whose values depend on $x_{t-1}$. The constant term of the polynomial is put to one to obtain a unique representation. This normalization means that the leading term of the entire expansion is $n\left(y_{t} \mid \mu_{x_{t-1}}, \sigma_{x_{t-1}}\right) .^{7}$ The location function $\mu_{x_{t-1}}$ is given by an autoregression

$$
\mu_{x_{t-1}}=b_{0}+B x_{t-1}
$$

It is assumed to depend on $L_{\mu} \leq L$ lags. The scale function $\sigma_{x_{t-1}}$ is given by

$$
\sigma_{x_{t-1}}=\rho_{0}+P\left|e_{t-1}^{*}\right|
$$

where $e_{t-1}^{*}=\left[\left(y_{t-L_{r}}-\mu_{x_{t-L_{r}-1}}\right), \cdots,\left(y_{t-1}-\mu_{x_{t-2}}\right)\right]$, and $|\cdot|$ denotes elementwise absolute value. The scale function depends on $L_{r}$ lagged (unnormalized) innovations $\left(y_{t}-\mu_{x_{t-1}}\right)$ and $\left(L_{\mu}+L_{r}\right) \leq L$ lagged $y_{t}$ in total. This is an ARCH-type process akin to that proposed by Nelson (1991).

The Hermite polynomial $P\left(z_{t}, x_{t-1}\right)$ is given by

$$
P\left(z_{t}, x_{t-1}\right)=\sum_{\alpha=0}^{K_{z}}\left(\sum_{\beta=0}^{K_{x}} a_{\alpha \beta} x_{t-1}^{\beta}\right) z_{t}^{\alpha}
$$

where $\alpha \leq K_{z}$ and $\beta \leq K_{x}$ are non-negative integers. It is assumed that the polynomial depends on $L_{p} \leq L$ lags of $y$ from $x$.

\footnotetext{
${ }^{6}$ Therefore $\xi=1 / \int[P(s, x)]^{2} \phi(s) d s$.

${ }^{7}$ The vector $\theta$ of $f\left(y_{t} \mid x_{t-1}, \theta\right)$ consists of the coefficients of the polynomial plus $\mu_{x_{t-1}}$ and $\sigma_{x_{t-1}}$ and is estimated by maximum likelihood. Equivalent to maximum likelihood, but more stable numerically, is to estimate $\theta$ in a sample of size $n$ by minimizing $s_{n}(\theta)=-\frac{1}{n} \sum_{t=1}^{n} \log \left[f\left(y_{t} \mid x_{t-1}, \theta\right)\right]$. If the number of parameters $p_{\theta}$ grows with the sample size $n$, then the true density, its derivatives, and moments are estimated consistently as shown in Gallant and Nychka (1987).
} 
When $K_{z}$ is positive, the resulting density function is a modification of the Gaussian due to the multiplication by the polynomial $\left\{P\left(z_{t}\right)\right\}^{2}$. When $K_{x}$ is positive, the shape of the density will depend on $x_{t-1}$. Thus, all moments can depend on $x_{t-1}$ and the density can approximate any form of conditional heterogeneity (Gallant and Tauchen, 1989). The shape modifications are rich enough to accurately approximate densities from a large class that includes densities that have fat tails, thin tails, or are skewed. ${ }^{8}$

For notational convenience, hereafter, the hierarchical SNP structure is denoted as $\operatorname{SNP}\left(L_{\mu}\right.$, $\left.L_{r}, L_{p}, K_{z}, K_{x}\right)$. To illustrate, consider first the model with $L_{\mu}=4, L_{r}=4, L_{p}=0, K_{z}=4$, and $K_{x}=0$. The polynomial is of the form

$$
P\left(z_{t}\right)=\sum_{\alpha=0}^{4} a_{\alpha} z_{t}^{\alpha}
$$

where the $a_{0}, a_{1}, \cdots, a_{4}$ are the polynomial coefficients with the constant term $a_{0}=1$ to achieve a unique representation. Both $\mu_{x_{t-1}}$ and $\sigma_{x_{t-1}}$ are linear in $y_{t-1}, \cdots, y_{t-4}$. The model has fourteen free parameters: the four free polynomial parameters, the intercept and four slope parameters in $\mu_{x_{t-1}}$, and the intercept and four slope parameters of $\sigma_{x_{t-1}}$.

Now consider $L_{p}=1$ and $K_{x}=1$ but everything else the same. The polynomial becomes

$$
P\left(z_{t}, x_{t-1}\right)=\sum_{\alpha=0}^{4}\left(a_{0 \alpha}+a_{1 \alpha} y_{t-1}\right) z_{t}^{\alpha} .
$$

The normalization is $a_{00}=1$. The polynomial has nine free parameters, yielding nineteen free parameters in total.

To select the optimal SNP model for the real returns, the following strategy is adopted. We start with a VAR process, $\operatorname{SNP}(10100)$, and gradually expand $L_{\mu}$ until certain model selection criterion reaches a minimum. Three model selection criteria are calculated for each SNP fit: the Schwarz criterion $\left[s_{n}+\frac{p_{\theta}}{2 n} \ln (n)\right]$, the Hannan-Quinn criterion $\left[s_{n}+\frac{p_{\theta}}{n} \ln [\ln (n)]\right]$, and the Akaike criterion $\left[s_{n}+\frac{p_{\theta}}{n}\right]$. We then introduce $\mathrm{ARCH}$ by increasing $L_{r}$, introduce non-Gaussian $\mathrm{ARCH}$ by increasing $K_{z}$, and finally bring in general nonlinear processes by increasing $L_{p}$ and $K_{x}$.

The preferred models are then subject to a battery of diagnostic tests to determine the goodness-of-fit. The diagnostic tests entail checking for predictability in the residuals from

\footnotetext{
${ }^{8}$ Fenton and Gallant (1996) assess the qualitative behavior of SNP in finite samples using the Marron and Wand (1992) test suite. For each of the fifteen densities proposed by Marron and Wand, Fenton and Gallant generate samples at sizes 400, 900, 1600, 2500, and 5625. To each they fit a kernel and SNP. For both kernel and SNP, they compute a Riemann sum of the absolute value of the distance between the estimated density and the true density on 1024 points evenly spaced over the interval [-3,3]. Their results suggest that the SNP estimator for a univariate series is both qualitatively and asymptotically similar to the kernel estimator.
} 
each SNP model. Residuals are examined for both short term and long term predictability of the mean (residual levels) and variance (squared residuals). For the long term tests, the residuals and their squares are projected onto annual dummy variables. For the short term tests, the residuals and their squares are projected onto a space formed by the linear, quadratic, and cubic terms of past variables (three lags are used). If an SNP model is the true density, the residuals should be orthogonal to the above regressors. Therefore, for a given SNP specification, the smaller the R-squared of the regressions, the better the SNP model approximates the true density.

Table 2 presents the SNP estimation results along with the model selection criteria. Both the Schwarz and Hannan-Quinn preferred model is $\operatorname{SNP}(11120)$. It is a non-Gaussian $\mathrm{ARCH}$ model with mean and variance functions depending linearly on $x_{t-1}$ with one lag. The model also has a quadratic polynomial in the innovations. The Akaike preferred model is $\mathrm{SNP}(11141)$. It is a full nonlinear process with a quartic polynomial whose coefficients are linear in $x_{t-1}$ with one lag. We choose the $\operatorname{SNP}(11141)$ as our final fit based on the diagnostic tests discussed above. ${ }^{9}$ The model has 13 parameters and a saturation ratio of fifteen. ${ }^{10}$

\subsubsection{Estimates of the Structural Parameters}

We use the bivariate $\operatorname{VAR}(1)$ for consumption and dividend growth rates discussed in Section 2 as our exogenous driving force. The structural parameters that we are interested in estimating consist of the discount factor $(\beta)$, the curvature parameter $(\gamma)$, and the persistence of the surplus consumption ratio $(\phi)$. Thus, the $\rho$ vector can be represented by $\rho=(\beta, \gamma, \phi)^{\prime}$.

Because the series to be matched is stock returns, we create a simulated stock return series from the model by taking the following steps. First, we simulate a long series of the exogenous variables including the consumption and dividend growth rates. We then recursively calculate the corresponding surplus consumption ratio and the stock prices using equations (10), (11), and (12) starting from the steady state surplus consumption ratio, $\bar{s}$, which is a function of the structural parameters, $\rho$. Finally, we calculate the simulated stock returns as follows:

$$
r_{i}=\frac{\left(\tilde{P}_{i}+1\right) \frac{D_{i}}{D_{i-1}}}{\tilde{P}_{i-1}}-1, \quad i=1,2, \cdots, N
$$

where $N$ is the length of simulation and is chosen to be 30,000 in our estimation. The first

\footnotetext{
${ }^{9}$ The results of diagnostic tests are not reported and are available upon request.

${ }^{10}$ The saturation ratio is defined as the total number of observations divided by the number of parameters estimated. Portnoy (1985) gives the maximum number of parameters in a linear regression as a function of sample size such that asymptotic normality of a linear function of the parameters is preserved. However, to our knowledge, no similar studies have been done in a nonlinear analysis such as ours.
} 
8,000 simulations are discarded before we collect observations for our estimation to remove possible transient effects of initial conditions. It is important to use a large $N$ to get reliable estimates when the persistence parameter is close to one.

Table 3 reports the EMM estimates for the structural parameters along with their numerical Wald standard errors and $t$-ratios. The point estimate for the discount factor is 1.007 with a standard deviation of 0.004. This is higher than the discount factor used in Campbell and Cochrane (0.971). While most research restricts the discount factor to be between 0 and 1 , it is possible for competitive equilibria to prevail even when $\beta$ is greater than 1 (see Kocherlakota, 1990). The curvature parameter is found to be 6.274 with a standard deviation of 0.14. This is much larger than the value of 2.0 used in Campbell and Cochrane and is beyond the 'reasonable' range based on the existing literature, for instance, Hansen and Singleton $(1982,1983)$. The estimated persistence parameter of the surplus consumption ratio is 0.912 with a standard deviation of 0.0015 and is smaller than the value used by Campbell and Cochrane (0.97). All three estimates are very highly statistically significant as shown by large $t$-ratios for the estimates.

The implied steady state surplus consumption ratio $(\bar{S})$ is 0.047 which implies a steady state habit level of 95.3 percent of consumption. The upper limit for the surplus consumption ratio is 0.077 which implies a minimum habit level of 92.3 percent of consumption. In Figure 1, we plot the sensitivity function for the estimated model. It shows that values taken by the sensitivity function $\lambda$ is above 15 around the steady state surplus consumption ratio $(\bar{s}=-3.064)$ and is above 5.0 almost everywhere except for the tiny region around the upper limit for the surplus consumption ratio $\left(s_{\max }=-2.564\right)$. As we have discussed in Section 2 , the cyclicality of expected stock returns is sensitive to how the surplus consumption ratio reacts to contemporaneous consumption growth rate. If the surplus consumption ratio reacts strongly to contemporaneous consumption growth rate ( $\lambda$ takes large values), then expected stock returns are countercyclical. Otherwise, they are procyclical. The sensitivity function for our parameter estimates thus implies that the economic model is likely to generate countercyclical expected stock returns.

The economic model is nonetheless rejected according to the chi-square statistic $\left(\chi^{2}(10)=\right.$ 25.585). The rejection is not overwhelming (The corresponding $p$-value is 0.0043 . We thus reject the model at the one percent but not at the 0.1 percent level) compared with tests of other consumption-based equilibrium asset pricing models using GMM. This justifies why Campbell and Cochrane find the model performing reasonably well in terms of explaining some of the stylized facts on the stock market.

The model fails dramatically with regard to the implications for the risk-free rate. By specifying i.i.d. consumption growth and a particular functional form for the evolution of the 
surplus consumption ratio, Campbell and Cochrane impose a constant risk-free rate on their model. Considering the relatively small amount of variation in the data, especially relative to equity returns, this is a very reasonable assumption. We adopted the same functional form for the evolution of $s_{t}$, but allowed for predictability in consumption growth as well as covariation with dividend growth. This resulted in a time varying risk-free rate. We did not use data on the risk-free rate during estimation. The mean risk-free rate implied by our point estimates is $-22.94 \%$ with a standard deviation of $12.05 \%$. This result is due in large part to the high estimate for the curvature parameter. Using Campbell and Cochrane's value of $\gamma=2$ along with our other point estimates results in an average risk-free rate of $-8.99 \%$.

We can further investigate which dimensions that the model fails to match by examining the score functions of the auxiliary model. Table 4 presents the normalized mean SNP scores along with the adjusted standard errors and the corresponding $t$-ratios for the estimated model. The results show that the model does a reasonable job in matching the mean function of the return series but it fails to match the variance and higher order moment functions as indicated by the high adjusted $t$-ratios for the variance function and some of the Hermite polynomial coefficients. The performance of the model can also be evaluated according to the conventional moments of returns. In Table 5, we present the comparison of four moments of the simulated stock returns and the real returns of S\&P 500 index portfolio. We have the following observations. The economic model matches the mean stock returns reasonably well though not perfectly. The variance of the simulated stock returns is however lower than its observed counterpart. The distribution of the simulated stock returns is skewed in the opposite direction as the observed returns. The economic model also fails to create the magnitude of the kurtosis observed in the real stock returns. While the real stock returns exhibit excessive kurtosis, the simulated stock returns show almost the same kurtosis as a normal distribution. Next, we discuss the robustness of our parameter estimates.

\subsubsection{Robustness of Parameter Estimates}

A number of recent studies (Andersen, Chung, and Sorensen, 1999, and Liu and Zhang, 1996) document that EMM estimation may be sensitive to the selection of auxiliary models. To address the issue on robustness, we re-estimate our structural model using an alternative auxiliary model, SNP(11121), in the EMM estimation. The alternative auxiliary model is also a full nonlinear process and has a quadratic Hermite polynomial whose coefficients are linear in $x_{t-1}$ with one lag.

Table 6 presents the results of our EMM estimation with the alternative auxiliary model $\mathrm{SNP}(11121)$. The point estimates for all three parameters are larger than the ones docu- 
mented above for the preferred auxiliary model SNP(11141). The estimate for the discount factor goes up from 1.0071 to 1.0136, and the curvature parameter estimate increases from 6.274 to 8.731 . The estimate for the persistence parameter, however, is only slightly larger (from 0.912 to 0.929 ). The estimates also are less efficient than the ones estimated with our preferred auxiliary model. The standard errors of all three parameter estimates are larger than those estimated with the preferred SNP model while the $t$-ratios of the parameter estimates are all smaller than that estimated with the preferred SNP model. The structural model is again rejected at the one percent test level according to the chi-squared test with a $p$-value of 0.0062 . While this is consistent with our early finding when the preferred SNP model is used, it also seems to indicate that the economic model fits the data better as reflected in the higher $p$-value. A possible explanation is the following. The simpler auxiliary model does not capture the higher order moment characteristics of the return data as well as the more complicated preferred SNP model. ${ }^{11}$ Consequently, it is relatively easier for the structural model to match the scores of the simpler model than to match the scores of the more complicated model.

\section{Cyclicality of Expected Stock Returns}

In this section, we first document some benchmark results on the cyclical behavior of the expected stock returns on the S\&P 500 index portfolio. We then investigate the cyclicality of the expected returns implied in our economic model using the structural parameters estimated in the previous section.

\subsection{Cyclicality of Expected Stock Returns: Empirical Evidence}

Many empirical studies ${ }^{12}$ have documented that stock returns can be predicted by means of publicly available information such as time series data on financial and macroeconomic variables with an important business cycle component. While a wide range of variables have been used for predicting stock returns, four variables, the dividend yield, the earnings-price ratio, the default premium, and the term premium, are consistently found to be important predictors. We therefore choose the above four variables as our predictors for expected stock

\footnotetext{
${ }^{11}$ Fenton and Gallant (1996) document that high order polynomials of the Hermite expansion are needed to accommodate highly skewed distributions. Similar results are also reported in Liu and Zhang (1996).

${ }^{12}$ An incomplete list includes Balvers, Cosimano, McDonald (1990), Bekaert and Hodrick (1992), Breen, Glosten, and Jagannathan (1989), Campbell (1987), Cochrane (1991), Fama and French (1989), Ferson and Harvey (1993), French, Schwert, and Stambaugh (1987), Glosten, Jagannathan, and Runkle (1993), Pesaran and Timmermann (1995), among others.
} 
returns of the S\&P 500 index portfolio.

For notational convenience, we denote $r(t, t+\tau)$ as the return of holding a stock purchased at time $t$ for $\tau$ periods, $d y_{t}$ as the dividend yield, $e p_{t}$ as the earnings-price ratio, $d p_{t}$ as the default premium, and $t p_{t}$ as the term premium. Let $X_{t}=\left[d y_{t}, e p_{t}, d p_{t}, t p_{t}\right]^{\prime}$. Following Fama and French (1989), to get expected returns, we regress the holding returns on the above four variables, $X_{t}$, known at time $t$ :

$$
r(t, t+\tau)=\alpha(\tau)+\beta(\tau) X_{t}+\epsilon_{t, t+\tau}
$$

We use quarterly data from the first quarter of 1947 to the fourth quarter of 1993 . The data set consists of real S\&P 500 value weighted returns, S\&P 500 dividend yield, S\&P 500 earnings-price ratio, the default premium measured by the difference between the average yield of Baa and Aaa corporate bonds, and the term premium measured by the difference between the average yield of Aaa corporate bonds and three month Treasury bill rates. The real returns are created by adjusting the nominal returns for the consumer price index. The term premium measure used here follows Kandel and Stambaugh (1990) and is slightly different from that in Fama and French (1989) in which the term premium is defined as the difference between the average yield of the long term government bonds and short term treasury bills. The S\&P 500 value weighted returns and three month treasury bill rates are from CRSP database and the rest of series are from CITIBASE.

In Table 7 we present the results for the above regression for $\tau=1,4,8$, and 20 which correspond to quarterly, annual, two year, and five year stock returns. The Newey-West (1987) estimate for the variance-covariance matrix is employed to correct for the heteroskedasticity and serial correlation of the error terms. The following features emerge. The dividend yield is consistently positive and statistically significant at the one percent level at all horizons reported. The earnings-price ratio, on the other hand, is consistently negative and statistically significant at the 5 percent level at a five year horizon. The default premium is positive at a quarterly horizon and negative at all longer horizons (annual, two, and five years) but not statistically significant. Finally the term premium is consistently positive and statistically significant at short horizons (quarterly and annually) but not at long horizons (two and five years).

Given the estimates of $\alpha(\tau)$ and $\beta(\tau)$, the expected stock returns predicted by the linear model, denoted $r(t \widehat{t+} \tau)$, are obtained from

$$
r(\widehat{t, t}+\tau)=\hat{\alpha}(\tau)+\hat{\beta}(\tau) X_{t}
$$


Figure 2 shows the expected stock returns along with the NBER classification of business cycle turning points for one quarter, one year, two year, and five year holding periods. It shows that the expected returns often reach the peak when the economy is in a recession. The phenomenon becomes more pronounced as the horizon increases.

To explore how expected stock returns are related to business cycles quantitatively, we estimate the following simple linear models as in Harrison and Zhang (1999):

$$
r(t \widehat{t+}+\tau)=\theta_{0}+\theta_{1} D_{t}+u_{t+1}
$$

where $D_{t}$ is the dummy variable created according to the NBER classification of business cycle turning points. ${ }^{13}$ It takes value one if period $t$ is in a recession (between a peak and a trough) and zero otherwise.

The top panel of Table 8 presents the regression results for the expected stock returns with different holding periods. The estimated coefficients of the dummy variable are consistently positive indicating that the expected stock returns are higher in recessions than in nonrecession periods at all horizons. Furthermore, the statistical significance of the recession dummy increases as the horizon expands. At a quarterly horizon, the estimate is positive and significant at the 3 percent level. However, at five year horizon, it is positive and statistically significant at the $0.2 \%$ level. The forecasting power of the business cycle variable also increases from about 1.9 percent to 5.1 percent as the horizon increases from a quarter to five years.

\subsection{Expected Stock Returns and the External Habit}

To obtain expected stock returns implied by the economic model, we use a numerical simulation method discussed below. Denote by $r_{\tau}^{e}(z(k), S(k)), \tau=1, \cdots, \infty$, the expected return of holding the stock for $\tau$ periods starting from the state $(z(k), S(k))$. Let $\pi\left(z_{\tau} \mid z_{\tau-1}\right)$ be the transition matrix for the exogenous state variables $\left(z_{t}\right)$ as defined by equation (8). Given the law of motion for the stock price as defined by equations (13) and (14) and the transition matrix for the exogenous state variables, the expected holding returns implied by the economic model can then be obtained using the following Monte Carlo integration. Denote by $\{z(k)\}, k=1, \cdots, K+N$, a long series of simulated exogenous state variables starting from the unconditional mean. Let $\{S(k)\}, k=1, \cdots, K+N$ be the corresponding surplus consumption ratio computed using Equations (11) and (12) starting from the steady

\footnotetext{
${ }^{13}$ The qualitative features of the cyclical behavior of the expected stock returns are unchanged when other business cycle proxies such as consumer confidence index and industrial product growth are used. See Harrison and Zhang (1999).
} 
state value $\bar{S}$. We drop the first $N$ observations to remove possible transient effects. Let $\left\{z_{i}^{j}(k)\right\}_{i=1}^{\tau}, j=1,2, \cdots, J$, be $J$ simulated realization path of the exogenous state variables starting from $z=z(k)$. Each path consists of $\tau$ simulated values for the exogenous state variables using the transition matrix $\pi(\cdot \mid \cdot)$. In other words, $z_{1}^{j}(k)$ is a random draw from $\pi\left(z^{\prime} \mid z(k)\right), z_{2}^{j}(k)$ is a random draw from $\pi\left(z^{\prime} \mid z_{1}^{j}(k)\right)$, and so forth. We first compute the surplus consumption ratio, $\left\{S_{i}^{j}(k)\right\}_{i=1}^{\tau}, j=1, \cdots, J$, starting from $S=S(k)$. We then recursively compute the stock price, $\tilde{P}_{i}^{j}\left(z_{i}^{j}(k), S_{i-1}^{j}(k)\right)$ for $i=1, \cdots, \tau$ and $j=1, \cdots, J$. The expected returns of holding the stock for $\tau$ periods corresponding to state $(z(k), S(k))$ can thus be approximated as follows:

$$
1+r_{\tau}^{e}(z(k), S(k)) \approx \frac{1}{J} \sum_{j=1}^{J} \frac{\tilde{P}_{1}^{j}+1}{\tilde{P}(z(k), S(k))} \frac{\tilde{P}_{2}^{j}+1}{\tilde{P}_{1}^{j}} \cdots \frac{\tilde{P}_{\tau}^{j}+1}{\tilde{P}_{\tau-1}^{j}} \exp \left(\Delta d_{1}^{j}\right) \cdots \exp \left(\Delta d_{\tau}^{j}\right)
$$

In our application, the length of the simulated series is set at $K=20,000$ with the initial $N=8,000$ observations discarded to remove possible transient effects. To be consistent with our empirical investigation, we compute the expected returns for $\tau=1,4,8$, and 20 , which corresponds to one quarter, one year, two year, and five year holding periods, respectively. The number of replications in computing the expected returns $(J)$ is set at 20,000.

To investigate the cyclical behavior of the expected stock returns we first construct dummy variables representing business cycles in the economic model. We then apply the similar business cycle regressions as in the previous subsection to the expected simulated stock returns. Following Rouwenhorst (1995), we define a recession as an episode starting at a period that the consumption growth rate is negative for two consecutive quarters. An alternative and more restrictive definition of a recession is that both the consumption and dividend growth rates are negative for two consecutive quarters. The dummy variable then takes value 1 if the economy is in a recession and 0 otherwise. We denote by $D 1$ the business cycle dummy corresponding to the first definition and by $D 2$ to the second definition. In the bottom panel of Table 8 we present the results of regressing the expected simulated returns at various horizons on the business cycle dummy variables.

Comparing to the expected returns of the S\&P 500 index portfolio, we have the following observations. First, the magnitude of the expected simulated returns are comparable to the observed counterpart at all four holding horizons during non-recession periods. For instance, the average expected returns of the S\&P 500 index during non-recession periods are $2.01 \%, 8.48 \%, 17.68 \%$, and $46.5 \%$ at one quarter, one year, two years, and five years, respectively. The average expected simulated returns during non-recession periods are $1.82 \%$, $7.11 \%, 14.59 \%$, and $41.01 \%$, for the same set of holding horizons, respectively, when the less 
stringent definition of recession $\left(D_{1}\right)$ is used. Similar results are also found for the more stringent definition of a recession $\left(D_{2}\right)$ as demonstrated in the bottom half of the lower panel in Table 8. This is consistent with our earlier finding that the model with the external habit does a reasonable job matching the mean of stock returns. Second, the expected simulated returns are procyclical at short holding horizon such as one quarter and countercyclical at all other longer horizons such as one year, two years, and five years. The countercyclical expected returns at longer horizons are consistent with the cyclical bahavior of the expected returns of the data.

A possible explanation is as follows. First, consumption growth tends to drive the expected stock returns procyclically. This is because consumption growth is positively serially correlated. A low consumption growth rate now (a recession) is likely to be followed by a low consumption growth rate next period. This would push up the current stock price according to the equilibrium stock pricing function and lead to a lower expected stock return. The surplus consumption ratio, on the other hand, exerts its influence on the expected returns via its impact on the growth rate of the surplus consumption ratio, which in turn depends on the sensitivity of the surplus consumption ratio to contemporaneous consumption growth rate. If the surplus consumption ratio is not sensitive to the consumption growth rate or the external habit level moves at about the same rate as consumption and in the same direction, then the growth rate of the surplus consumption ratio for the next period will not be significantly affected. As a result, the expected stock returns is basically affected by the consumption growth rate, which is procyclical. On the other hand, if the surplus consumption ratio reacts strongly to the contemporaneous consumption growth rate, then when the economy is in a recession, the current surplus consumption ratio will decrease significantly. The growth rate of the surplus consumption ratio thus increases and the stock price goes down. The expected stock return will be higher. When the latter effect dominates the former, the overall effect will move the expected stock return countercyclically.

Furthermore, the spread of the expected returns between recession and non-recession periods is much smaller for the simulated returns than for the observed returns. For instance, the spread for the simulated returns is about $1 \%, 3 \%$, and $8 \%$ at one year, two years, and five years, respectively. The spread for the observed returns, however, is more than $4 \%, 7 \%$, and $27 \%$, respectively, for the same holding horizons. This is consistent with our earlier finding that the economic model fails to match the variance of observed stock returns. The finding suggests that while we have limited success in replicating the cyclical behavior of expected stock returns by introducing the external habit, it remains an important challenge for economic models to match the large spread in expected returns between recession and non-recession periods observed in the data. 


\section{Conclusions}

In this paper we extend the Campbell and Cochrane (1999) study by formally estimating an equilibrium asset pricing model in which agents' preferences have an unobserved external habit using the efficient method of moments proposed by Bansal, Gallant, Hussey and Tauchen (1994) and Gallant and Tauchen (1996). We find that the estimated subjective discount factor to be slightly greater than one supporting the earlier finding by Kocherlakota (1990). The surplus consumption ratio process is very persistent as reflected by a larger than 0.9 persistence parameter in the law of motion for the surplus consumption ratio. Our estimation results suggest that the surplus consumption ratio reacts strongly positively to the contemporaneous consumption growth rate. This implies that the external habit moves at a slower rate than consumption. The model with the external habit therefore generate countercyclical expected stock returns at all longer holding periods such as one year, two years, and five years. It also generates expected stock returns comparable to the expected returns of the S\&P 500 index portfolio for non-recession periods. This is consistent with the limited success of the Campbell and Cochrane study in replicating some of the stylized facts of the stock market using the model with the external habit.

The model, however, fails to create the large spread of expected returns between the recession and non-recession periods observed in the $\mathrm{S} \& \mathrm{P} 500$ index returns. Further, the model is rejected at the one percent (but not at the 0.1 percent) significance level according to the chi-square test. Detailed examination of the score functions of the auxiliary model and the conventional moments indicates that while the model does a reasonable job in matching the mean of the real returns, it fails to match the higher order moments. The model implies negative risk-free rates using our point estimates indicating the sensitivity of the specification of the law of motion for the surplus consumption ratio to small perturbations of other dimensions of the model such as allowing for predictability of consumption growth and covariation with dividend growth.

\section{References}

Abel, Andrew B., 1990, Asset prices under habit formation and catching up with the Joneses, American Economic Review 80, 38-42.

Andersen, Torben G., Hyung-Jin Chung, and Bent E. Sorensen, 1999, Efficient method of moments estimation of a stochastic volatility model: A Monte Carlo study, Journal of Econometrics 91, 61-87. 
Balvers, Ronald J., Thomas F. Cosimano, and Bill McDonald, 1990, Predicting stock returns in an efficient market, Journal of Finance 45, 1109-1128.

Bansal, Ravi, A. Ronald Gallant, Robert Hussey, and George Tauchen, 1993, Computational aspects of nonparametric simulation estimation, in David A. Belsley (ed.) Computational Techniques for Econometrics and Economic Analysis, (Boston: Kluwer Academic Publishers, 3-22).

Bansal, Ravi, A. Ronald Gallant, Robert Hussey, and George Tauchen, 1994, Nonparametric estimation of structural models for high-frequency currency market data, Journal of Econometrics 66, 251-287.

Bekaert, Geert and Robert J. Hodrick, 1992, Characterizing predictable components in excess returns on equity and foreign exchange markets, Journal of Finance 47, 467509.

Black, Fischer, 1990, Mean reversion and consumption smoothing, Review of Financial Studies 3, 107-114.

Breen, William, Lawrence R. Glosten, and Ravi Jagannathan, 1989, Economic significance of predictable variations in stock index returns, Journal of Finance 44, 1177-1189.

Campbell, John Y., 1987, Stock returns and the term structure, Journal of Financial Economics 18, 373-399.

Campbell, John Y. and John H. Cochrane, 1999, By force of habit: A consumption-based explanation of aggregate stock market behavior, Journal of Political Economy 107, 205-251.

Cochrane, John H., 1991, Production-based asset pricing and the link between stock returns and economic fluctuations, Journal of Finance 46, 209-238.

Den Haan, Wouter J. and Albert Marcet, 1990, Solving the stochastic growth model by parameterizing expectations, Journal of Business and Economic Statistics 8, 31-34.

Eichenbaum, Martin and Lars Peter Hansen, 1990, Estimating models with intertemporal substitution using aggregate time series data, Journal of Business and Economic Statistics 8, 53-69.

Fama, Eugene F., 1990, Stock returns, expected returns, and real activity, Journal of Finance $45,1089-1109$. 
Fama, Eugene F. and Kenneth R. French, 1989, Business conditions and expected stock returns, Journal of Financial Economics 25, 23-49.

Fenton, Victor M. and A. Ronald Gallant, 1996, Qualitative and asymmetric performance of SNP density estimators, Journal of Econometrics 74, 77-118.

Ferson, Wayne E. and George M. Constantinides, 1991, Habit persistence and durability in aggregate consumption, Journal of Financial Economics 29, 199-240.

Ferson, Wayne E. and Campbell R. Harvey, 1993, The risk and predictability of international equity returns, Review of Financial Studies 6, 527-566.

French, Kenneth R., G. William Schwert, and Robert F. Stambaugh, 1987, Expected stock returns and volatility, Journal of Financial Economics 19, 3-30.

Gallant, A. Ronald and Douglas W. Nychka, 1987, Semiparametric maximum likelihood estimation, Econometrica 55, 363-390.

Gallant, A. Ronald and George Tauchen, 1989, Seminonparametric estimation of conditionally constrained heterogeneous processes: Asset pricing applications, Econometrica 57, 1091-1120.

Gallant, A. Ronald and George Tauchen, 1996, Which moments to match? Econometric Theory, 12, 657-681.

Glosten, Lawrence R., Ravi Jagannathan, and David E. Runkle, 1993, On the relation between the expected value and the volatility of the nominal excess returns on stocks, Journal of Finance 48, 1779-1802.

Gourieroux, C., A. Monfort, E. Renault, 1993, Indirect Inference, Journal of Applied Econometrics 8, 85-118.

Hansen, Lars Peter and Kennethe J. Singleton, 1982, Generalized instrumental variable estimation of nonlinear rational expectations models, Econometrica 50, 1029-1054.

Hansen, Lars Peter and Kenneth J. Singleton, 1983, Stochastic consumption, risk aversion, and the temporal behavior of asset returns, Journal of Political Economy 91, 249-265.

Harrison, Paul and Harold H. Zhang, 1999, An investigation of the risk and return relation at long horizons, Review of Economics and Statistics 81, 399-408. 
Kandel, Shmuel and Robert F. Stambaugh, 1990, Expectations and volatility of consumption and asset returns, Review of Financial Studies 3, 207-232.

Kocherlakota, Narayana R., 1990, On the 'Discount' Factor in Growth Economies, Journal of Monetary Economics 25, 43-47.

Liu, Ming and Harold H. Zhang, 1996, Specification tests in the efficient method of moments framework with application to the stochastic volatility models, Working Paper \#1996E34, Carnegie Mellon University.

Ljungqvist, Lars and Harald Uhlig, 1999, On Consumption Bunching under CampbellCochrane Habit Formation, Working Paper No. 337, Stockholm School of Economics.

Ljungqvist, Lars and Harald Uhlig, 2000, Tax Policy and Aggregate Demand Management under Catching Up with the Joneses, American Economic Review 90, 356-366.

Marron, J. S. and M. P. Wand, 1992, Exact mean integrated squared error, Annals of Statistics 20, 712-736.

Nelson, Daniel B. (1991), 'Conditional heteroskedasticity in asset returns: A new approach', Econometrica, 59, 347-370.

Newey, Whitney K. and Kenneth D. West, 1987, A simple positive semi-definite heteroskedasticity and autocorrelation consistent covariance matrix, Econometrica 55, 703-708.

Pesaran, M. Hashem and Allan Timmermann, 1995, Predictability of stock returns: robustness and economic significance, Journal of Finance 50, 1201-1228.

Portnoy, Stephen, 1985, Asymptotic Behavior of $M$ Estimators of $p$ Regression Parameters when $p^{2} / n$ is Large; II. Normal Approximation, Annals of Statistics 13, 1403-1417.

Rouwenhorst, K. Geert, 1995, Asset pricing implications of equilibrium business cycle models, in Thomas F. Cooley (ed.) Frontiers of Business Cycle Research. Princeton: Princeton University Press.

Smith, A.A., Jr., 1993, Estimating Nonlinear Time Series Models Using Simulated Vector Autoregressions, Journal of Applied Econometrics 8, 63-84.

Zhang, Harold H., 1997, Endogenous short sale constraint, stock prices and output cycles, Macroeconomic Dynamics 1, 228-254. 


\begin{tabular}{c|c|c|cc|cc|cc}
\hline \hline Variable & Const. & Std. Errors & \multicolumn{2}{|c|}{ Slopes } & \multicolumn{2}{|c|}{ Std. Errors } & \multicolumn{2}{c}{ Var.-covar. Matrix } \\
\hline$\Delta c$ & .0032 & $4.827 \mathrm{e}-4$ & .1720 & .0267 & .0709 & .0128 & $2.849 \mathrm{e}-5$ & $2.141 \mathrm{e}-5$ \\
$\Delta d$ & .0023 & $2.249 \mathrm{e}-3$ & .5942 & .0558 & .4046 & .0728 & $.2141 \mathrm{e}-4$ & $.9264 \mathrm{e}-3$ \\
\hline
\end{tabular}

Table 1: Table 1. Vector Autoregression Coefficients for Exogenous Processes. $\Delta c$ denotes the per capita consumption growth rate of nondurables and services and $\Delta d$ represents the per capita dividend growth rate. The bivariate VAR is estimated using quarterly data from 1947:Q2 to 1995:Q3 taken from the CITIBASE dataset.

\begin{tabular}{cccccc}
\hline \hline Model & $p_{\theta}$ & $s_{n}$ & Schwarz & H-Q & Akaike \\
\hline $\mathrm{SNP}(10100)$ & 3 & 1.4143 & 1.4550 & 1.4399 & 1.4297 \\
$\mathrm{SNP}(11100)$ & 4 & 1.3985 & 1.4528 & 1.4328 & 1.4191 \\
$\mathrm{SNP}(12100)$ & 5 & 1.3979 & 1.4658 & 1.4407 & 1.4237 \\
$\mathrm{SNP}(11120)$ & 6 & 1.3675 & 1.4489 & 1.4189 & 1.3984 \\
$\mathrm{SNP}(11140)$ & 8 & 1.3531 & 1.4617 & 1.4217 & 1.3944 \\
$\mathrm{SNP}(11121)$ & 9 & 1.3507 & 1.4729 & 1.4277 & 1.3971 \\
$\mathrm{SNP}(11141)$ & 13 & 1.3130 & 1.4895 & 1.4244 & 1.3800 \\
$\mathrm{SNP}(20100)$ & 4 & 1.4109 & 1.4652 & 1.4452 & 1.4315 \\
\hline
\end{tabular}

Table 2: Table 2. SNP Estimation of the Density Function. The ex post real returns of the S\&P 500 index portfolio is constructed using quarterly nominal returns of the S\&P 500 index portfolio and inflation. The data spans the period from 1947:Q2 to 1995:Q3. The return series is taken from the CRSP tape and the inflation series is from the CITIBASE. $p_{\theta}$ is the number of parameters in the SNP model. $s_{n}$ is the objective value. Schwarz, HQ, and Akaike are the Schwarz, Hannan and Quinn, and Akaike model selection criterion, respectively.

\begin{tabular}{cccc}
\hline \hline Parameter & Estimate & Std. Error & $t$ ratio \\
\hline$\beta$ & 1.0071 & 0.0040 & 253.14 \\
$\gamma$ & 6.2740 & 0.1400 & 44.809 \\
$\phi$ & 0.9119 & 0.0015 & 597.66 \\
$\tilde{s}_{n}(\hat{\rho})$ & $\chi^{2}(10)=25.585$ & $p-$ value $=0.0043$ \\
\hline
\end{tabular}

Table 3: Table 3. EMM Estimates of Structural Parameters. The selected auxiliary model is $\operatorname{SNP}(11141) . \beta$ is the discount factor. $\gamma$ is the curvature parameter. $\psi$ is the persistence parameter. $\tilde{s}_{n}(\hat{\rho})$ is the normalized objective value evaluated at the estimated structural parameter values. $p$-value is the probability for the hypothesis test that the economic model is correctly specified under the null. 


\begin{tabular}{rcccc}
\hline \hline & & Score & Adj. Std. Err. & $t$ ratio \\
\hline Mean Function & $b_{0}$ & 0.4384 & 1.0042 & 0.437 \\
& $b_{1}$ & 1.3141 & 1.0855 & 1.211 \\
Variance Function & $r_{0}$ & -3.4395 & 1.1113 & -3.095 \\
& $r_{1}$ & -2.4692 & 1.1352 & -2.175 \\
Hermite Polynomial & $a(1)$ & -0.3127 & 0.5546 & -0.564 \\
$a(2)$ & 3.6624 & 1.6867 & 2.171 \\
$a(3)$ & -2.1406 & 1.5683 & -1.365 \\
$a(4)$ & 10.883 & 2.6153 & 4.161 \\
$a(5)$ & -3.2638 & 2.2656 & -1.441 \\
$a(6)$ & 12.813 & 6.7345 & 1.903 \\
$a(7)$ & -1.5308 & 7.1918 & -0.213 \\
$a(8)$ & 57.563 & 15.703 & 3.666 \\
$a(9)$ & -10.669 & 16.732 & -0.638 \\
\hline
\end{tabular}

Table 4: Table 4. $t$ Tests on Various Scores. The selected auxiliary model is SNP(11141). The scores are evaluated using simulated returns when the structural parameters are set at the

estimated values.

\begin{tabular}{ccc}
\hline \hline Moment & Real Returns & Simulated Returns \\
\hline Mean & 0.0216 & 0.0182 \\
Std. Err. & 0.0768 & 0.0461 \\
Skewness & -0.6450 & 0.2837 \\
Kurtosis & 4.4236 & 3.2869 \\
\hline
\end{tabular}

Table 5: Table 5. Summary Statistics of Stock Returns: A Comparison. The real returns are quarterly ex post real returns of the S\&P 500 index portfolio from 1947:Q2 to 1995:Q3. The simulated returns are obtained by setting the structural parameters at the estimated values. The summary statistics of simulated returns are based on 30,000 realizations.

\begin{tabular}{cccc}
\hline \hline Parameter & Estimate & Std. Error & $t$ ratio \\
\hline$\beta$ & 1.0136 & 0.0054 & 186.15 \\
$\gamma$ & 8.7309 & 0.5341 & 16.346 \\
$\phi$ & 0.9294 & 0.0926 & 10.035 \\
$\tilde{s}_{n}(\hat{\rho})$ & $\chi^{2}(6)=18.015 \quad p-$ value $=0.0062$ \\
\hline
\end{tabular}

Table 6: Table 6. EMM Estimates of Structural Parameters. The selected auxiliary model is $\operatorname{SNP}(11121) . \beta$ is the discount factor. $\gamma$ is the curvature parameter. $\psi$ is the persistence parameter. $\tilde{s}_{n}(\hat{\rho})$ is the normalized objective value evaluated at the estimated structural parameter values. $p$-value is the probability for the hypothesis test that the economic model is correctly specified under the null. 


\begin{tabular}{l|cccc}
\hline \hline Variable & Quarterly & Annual & Two Years & Five Years \\
\hline Constant & -.0828 & -.2947 & -.4466 & -1.3538 \\
& $(.0267)$ & $(.0860)$ & $(.1373)$ & $(.2237)$ \\
$d y$ & 14.885 & 53.230 & 101.616 & 269.383 \\
& $(5.505)$ & $(21.393)$ & $(33.415)$ & $(45.430)$ \\
$e p$ & -3.7041 & -10.596 & -20.338 & -46.077 \\
& $(2.127)$ & $(7.679)$ & $(11.906)$ & $(22.957)$ \\
$d p$ & .0084 & -.0027 & -.0445 & -.0375 \\
& $(.0159)$ & $(.0368)$ & $(.0430)$ & $(.1253)$ \\
$t p$ & .0099 & .0308 & .0244 & .0365 \\
& $(.0042)$ & $(.01445)$ & $(.0235)$ & $(.0436)$ \\
$\bar{R}^{2}$ & .0830 & .2493 & .3414 & .6843 \\
\hline
\end{tabular}

Table 7: Table 7. Regression of Real S\&P Returns on Dividend Yield $(d y)$, Earning Price Ratio $(e p)$, Default Premium $(d p)$, and Term Premium $(t p)$. The data set is quarterly from 1947:Q1 to 1993:Q4. The default premium is measured by the difference between the average yield of Baa and Aaa corporate bonds, and the term premium is measured by the difference between the average yield of Aaa corporate bonds and three month treasury bills. The real returns are created by adjusting the nominal S\&P 500 value weighted returns for inflation. Note: Numbers in parentheses are standard errors. 


\begin{tabular}{ccccc}
\hline Horizon & Variable & Param. & Standard & T for H0: \\
Estimate & Error & $\beta=0$ & Prob $>|T|$ \\
\hline
\end{tabular}

Data

\begin{tabular}{cccccc} 
Quarterly & Constant & .0201 & .0020 & 10.220 & .0001 \\
& DB & .0102 & .0047 & 2.157 & .0323 \\
\hline \multirow{2}{*}{1 Year } & Constant & .0848 & .0070 & 12.112 & .0001 \\
& DB & .0435 & .0169 & 2.573 & .0109 \\
\hline 2 Years & Constant & .1768 & .0120 & 14.699 & .0001 \\
& DB & .0759 & .0291 & 2.611 & .0098 \\
\hline 5 Years & Constant & .4650 & .0344 & 13.531 & .0001 \\
& DB & .2761 & .0831 & 3.323 & .0011 \\
\hline
\end{tabular}

Simulated Returns

\begin{tabular}{cccccc} 
Quarterly & Constant & 0.0182 & 0.0001 & 141.69 & 0.0001 \\
& D1 & -0.0070 & 0.0004 & -18.75 & 0.0001 \\
\hline 1 Year & Constant & 0.0711 & 0.0002 & 315.73 & 0.0001 \\
& D1 & 0.0098 & 0.0007 & 14.88 & 0.0001 \\
\hline 2 Years & Constant & 0.1459 & 0.0004 & 411.82 & 0.0001 \\
& D1 & 0.0340 & 0.0010 & 32.75 & 0.0001 \\
\hline 5 Years & Constant & 0.4101 & 0.0007 & 610.82 & 0.0001 \\
& D1 & 0.0854 & 0.0020 & 43.45 & 0.0001 \\
\hline \hline Quarterly & Constant & 0.0178 & 0.0001 & 144.26 & 0.0001 \\
& D2 & -0.0103 & 0.0006 & -17.60 & 0.0001 \\
\hline 1 Year & Constant & 0.0720 & 0.0002 & 330.90 & 0.0001 \\
& D2 & 0.0053 & 0.0010 & 5.19 & 0.0001 \\
\hline 2 Years & Constant & 0.1485 & 0.0003 & 428.23 & 0.0001 \\
& D2 & 0.0300 & 0.0016 & 18.27 & 0.0001 \\
\hline 5 Years & Constant & 0.4163 & 0.0007 & 627.14 & 0.0001 \\
& D2 & 0.0832 & 0.0031 & 26.51 & 0.0001 \\
\hline
\end{tabular}

Table 8: Table 8. Regression of Expected Stock Returns on the Business Cycle Proxy. DB is the business cycle dummy variable defined based on the NBER business cycle turning point classification. It takes value 1 when the economy is between a peak and a trough and takes value 0 otherwise. D1 is the first dummy variable defined for the economic model. It takes value 1 if the consumption growth rate is negative for two consecutive quarters and takes value 0 otherwise. D2 is the second dummy variable defined for the economic model. It takes value 1 if both consumption growth rate and dividend growth rate are negative for two consecutive quarters and takes value 0 otherwise. 


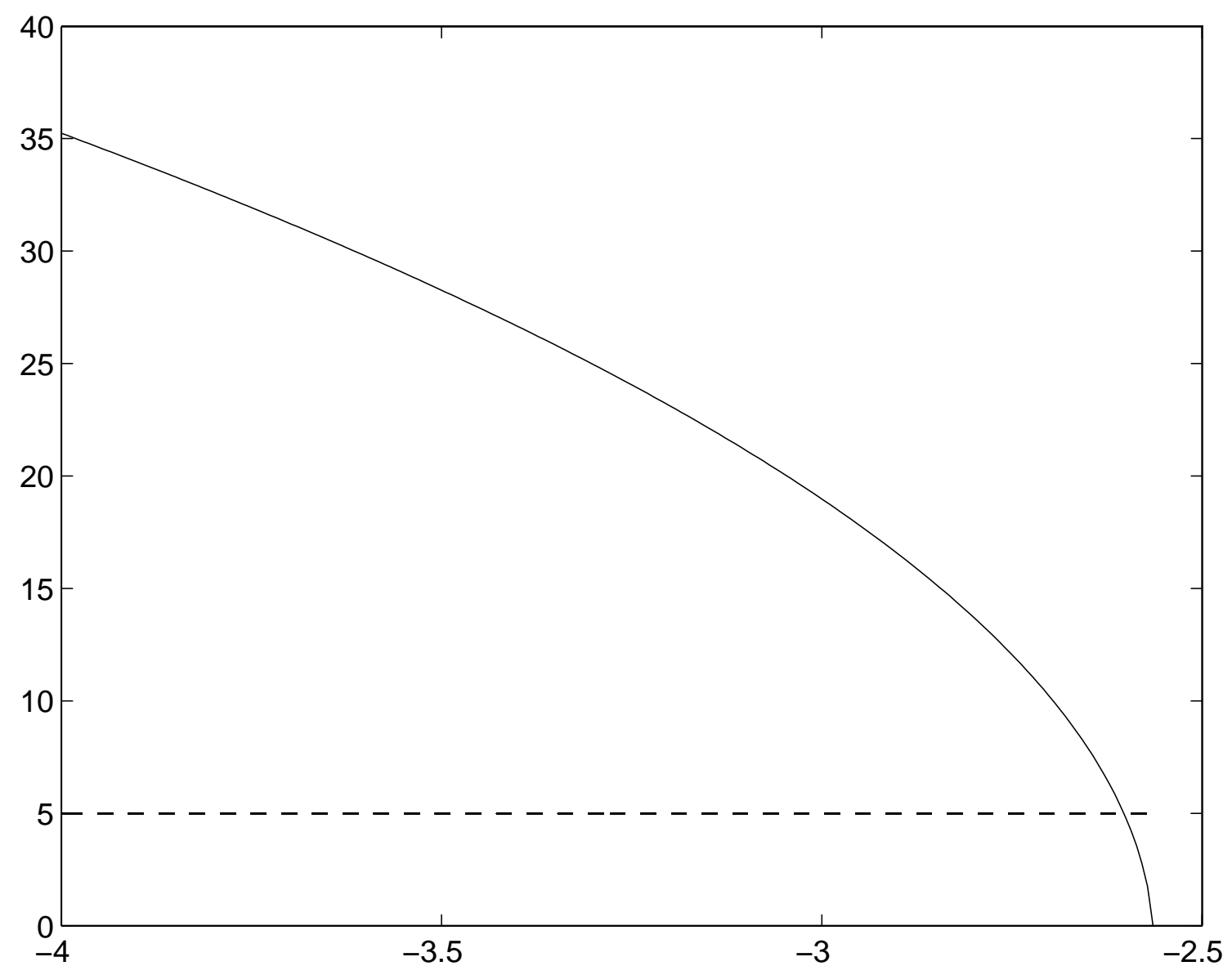

Figure 1: The sensitivity function $(\lambda)$ versus the surplus consumption ratio. The vertical axis is $\lambda$ and the horizontal axis is the logarithm of surplus consumption ratio, $s_{t}$. The dashed line corresponds to $\lambda=5.0$. 
(A)

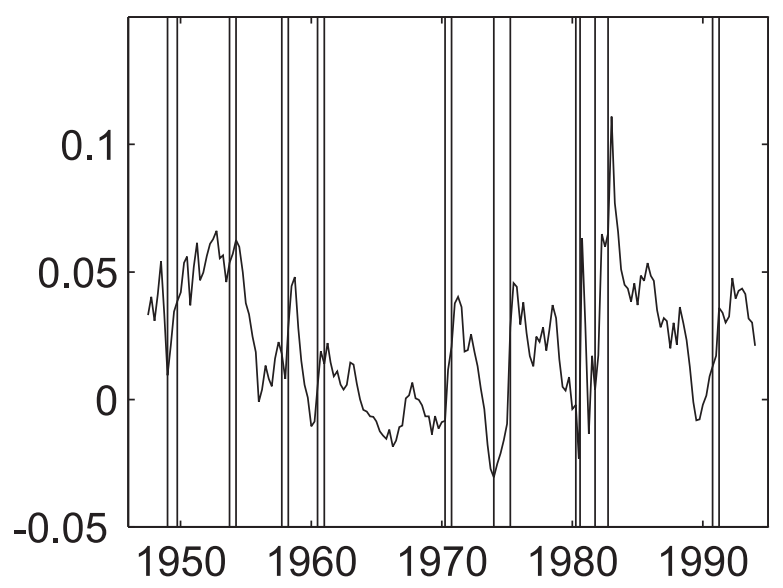

(C)

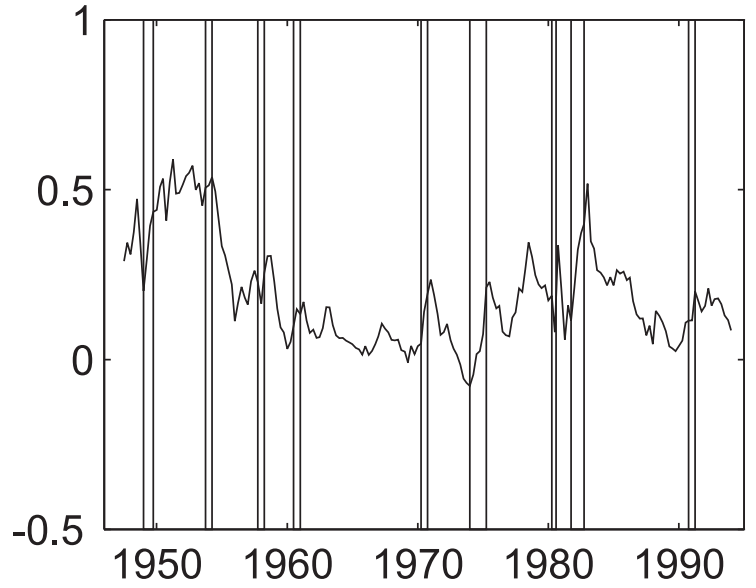

(B)

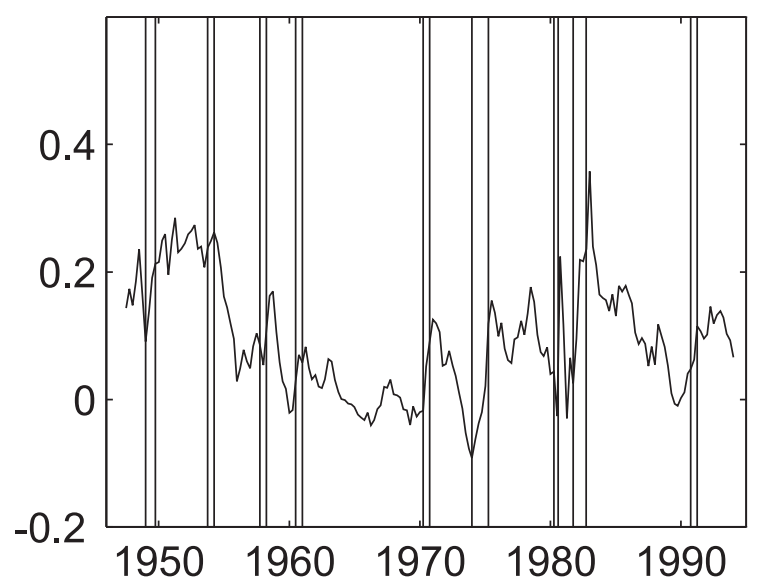

(D)

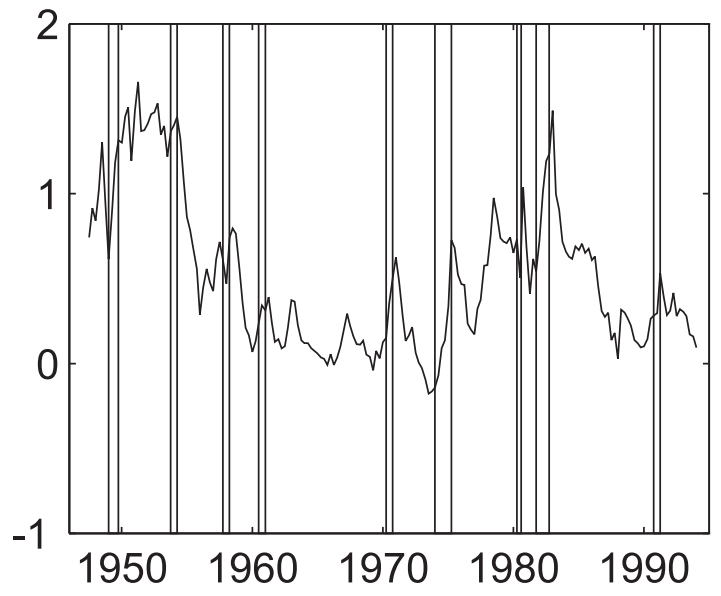

Figure 2: The expected stock returns at (A) quarterly, (B) annual, (C) two year, and (D) five year horizons. The vertical grid lines are NBER business-cycle peaks and troughs. 